\title{
Article \\ Effect of Phase Changes on the Axial Modulus of an FeMnSi-Shape Memory Alloy
}

\author{
Yajiao Yang ${ }^{1}$, Matteo Breveglieri ${ }^{1}$ (D) and Moslem Shahverdi ${ }^{1,2, *(D)}$ \\ 1 Empa, Swiss Federal Laboratories for Materials Science and Technology, 8600 Dübendorf, Switzerland; \\ yajiao.yang@empa.ch (Y.Y.); matteo.breveglieri@empa.ch (M.B.) \\ 2 School of Civil Engineering, University of Tehran, Tehran 4563-11155, Iran \\ * Correspondence: moslem.shahverdi@empa.ch or moslem.shahverdi@ut.ac.ir
}

Citation: Yang, Y.; Breveglieri, M.; Shahverdi, M. Effect of Phase Changes on the Axial Modulus of an FeMnSi-Shape Memory Alloy. Materials 2021, 14, 4815. https:// doi.org/10.3390/ma14174815

Academic Editor: Hideki Hosoda

Received: 26 July 2021

Accepted: 20 August 2021

Published: 26 August 2021

Publisher's Note: MDPI stays neutral with regard to jurisdictional claims in published maps and institutional affiliations.

Copyright: (c) 2021 by the authors. Licensee MDPI, Basel, Switzerland. This article is an open access article distributed under the terms and conditions of the Creative Commons Attribution (CC BY) license (https:// creativecommons.org/licenses/by/ $4.0 /)$.

\begin{abstract}
The axial modulus $E_{S M A}(\kappa)$ of FeMnSi-based shape memory alloys (FeMnSi-SMAs) is a parameter introduced in this study to characterize the relationship between stress and strain behavior at the early stage of tensile loading. $E_{S M A}(\kappa)$ can be used to correctly estimate and model the interaction forces between FeMnSi-SMAs and other materials. Unlike the conventional Young's modulus, which is usually given at room temperature, the $E_{S M A}(\kappa)$ is evaluated at different temperatures and strongly depends on phase transformation and plastic deformation. This study investigated the evolution of $E_{S M A}(\kappa)$ during and after pre-straining as well as in the course of the activation processes. The effect of different factors (e.g., phase transformation and plastic deformation) on the magnitude of $E_{S M A}(\kappa)$ is discussed. The result shows that the $E_{S M A}(\kappa)$ can differ significantly during activation and thus needs to be modified when interaction forces between FeMnSi-SMAs and other substrates materials (e.g., concrete) must be modeled and evaluated.
\end{abstract}

Keywords: FeMnSi-based shape memory alloys; axial modulus $E_{S M A}(\kappa)$; activation process; phase transformation; plastic deformation

\section{Introduction}

Shape memory alloys (SMAs) are unique alloys that can recover their shapes caused by deformation through unloading or upon heating above a specific temperature. Because of the shape memory effect (SME) and superelasticity, SMAs are widely applied in the automotive, aerospace, robotic, civil engineering, and biomedical domains [1-9]. NiTibased SMAs (NiTi-SMAs) have played a leading role in the industry owing to their good SME. However, they are high-priced, implying that they cannot be easily employed in large amounts as required in civil engineering. As an alternative to NiTi-SMAs, the FeMnSibased SMA (FeMnSi-SMA) has attracted considerable attention over the past two decades due to its low cost, good machinability, workability, and weldability [10]. For structural applications, a big advantage of an iron-based SMA is the significantly higher Young's modulus in comparison to NiTi-based products [11].

The mechanism governing the SME of a FeMnSi-SMA is the phase transformation between $\gamma$-austenite (face-centered cubic, FCC) and $\varepsilon$-martensite (hexagonal close-packed, $\mathrm{HCP})$, which is induced by the application of external stress and/or temperature changes. The undeformed FeMnSi-SMA mainly contains an unstable $\gamma$-austenite phase at room temperature. The $\gamma$-austenite phase can transform into $\varepsilon$-martensite with the application of external stress, and finally, change the shape of FeMnSi-SMA. The stress-induced $\varepsilon$ martensite can go back to $\gamma$-austenite upon heating above the austenite starting temperature $A_{S}$, and consequently, FeMnSi-SMA recovers its shape to some extent. Such a characteristic of FeMnSi-SMA has attracted significant attention from the industry.

In civil engineering, FeMnSi-SMAs have been used to prestress reinforced concrete members, such as slabs and bridge girders [12]. The prestressing effect, which develops after the SMA heating, keeps the concrete members in compression or in case of flexure 
and reduces the tensile strains, thus preventing or reducing crack propagation. It decreases the deflection of the structural elements and increases their service life [13-17]. Figure 1a shows, as an example, FeMnSi-SMA strips used as a flexural strengthening of a reinforced concrete slab, while Figure $1 \mathrm{~b}$ depicts FeMnSi-SMAs' bars applied to improve the shear carrying capacity of a beam. In the first application, the strips are constrained at the extremities; meanwhile, in the second, Fe-SMAs will be embedded in a cementitious shotcrete layer. For conventional prestressing elements, e.g., steels or carbon fiber reinforced polymers (CFRPs), complex anchoring and hydraulic systems are needed to induce prestress force [12]. However, in the case of FeMnSi-SMAs, the prestressing phase is simplified as there is no need to use sophisticated mechanical systems due to the shape memory effect.

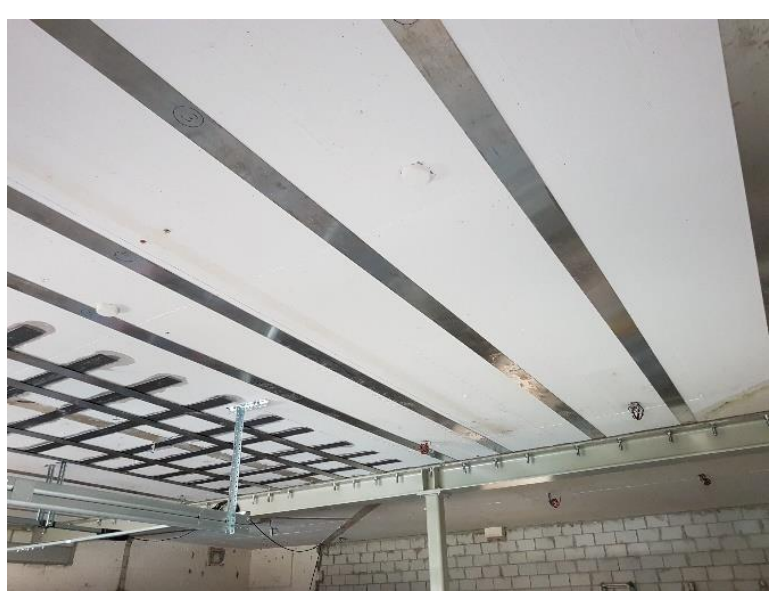

(a)

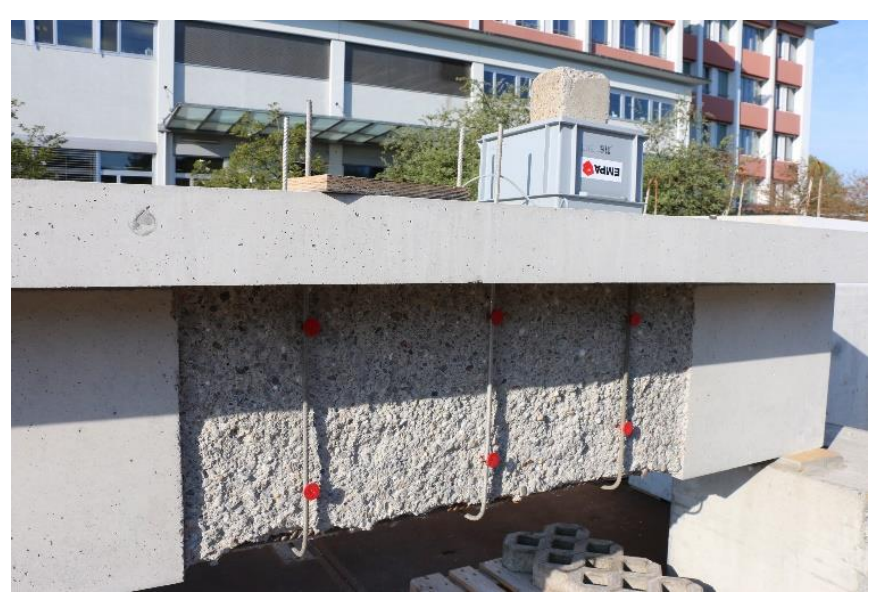

(b)

Figure 1. Application of FeMnSi-SMAs in civil engineering: (a) an example of FeMnSi-SMA strips used as a flexural strengthening of a reinforced concrete slab. (b) FeMnSi-SMA bars applied to improve the shear carrying capacity of a RC beam.

The prestressing effect in FeMnSi-SMAs is achieved by following three main steps. Step 1: pre-straining, which consists of deforming the FeMnSi-SMA material to the desired strain level to generate stress-induced martensite, followed by unloading after the deformation. Step 2: similar to a conventional steelwork, the FeMnSi-SMA strip can be fixed at its ends to the concrete [18], as shown in Figure 1a or alternatively, in the case of bars, it can be embedded in an additional cementitious layer (or shotcrete) [19], as shown in Figure 2a. Step 3: the SMA is heated up to a target temperature and cooled down to room temperature. This thermal process is called activation.

(a)

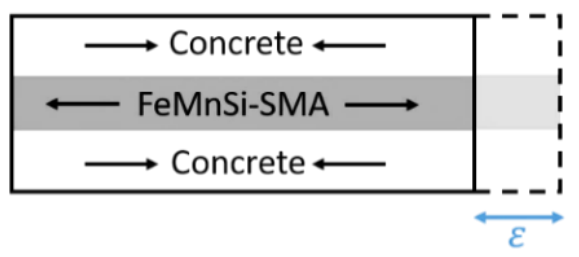

(b)

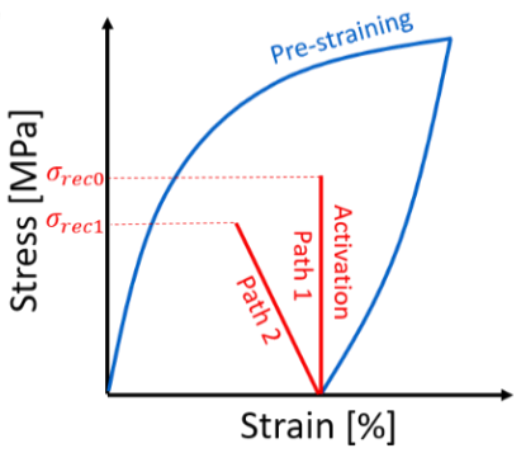

Figure 2. Schematic illustration of the interaction force between the concrete and the FeMnSi-SMA strip. (a) Example of activated FeMnSi-SMA material embedded into concrete, and (b) typical FeMnSi-SMA stress-strain diagram during the pre-straining and activation phase. 
Since the FeMnSi-SMA cannot return to its original configuration, stress is developed due to the reverse martensitic phase transformation upon heating (as illustrated in Figure 2a). The total stress achieved in the FeMnSi-SMA after the activation and cooling to room temperature is called recovery stress, $\sigma_{\text {rec }}$.

When FeMnSi-SMA strips or bars are fixed at their ends, the evolution of recovery stress during the activation process is shown as Path 1 in Figure $2 b$. However, in the case of non-fully rigid constraint, for example, flexible parent structure in Figure 1a [20], the evolution of the recovery stress obeys Path 2. In concrete-embedded FeMnSi-SMA, due to the concrete contraction, the recovery stress can be, for this reason, slightly lower. The relative stiffness between SMA and substrate rules the iteration forces between the materials. Their interaction can be expressed as a function of $\alpha$ [21]:

$$
\alpha=\frac{k_{C}}{k_{S M A}}=\frac{k_{C} L}{A_{S M A}} \cdot \frac{1}{E_{S M A}(\kappa)}
$$

where, $k_{C}$ and $k_{S M A}$ are the axial stiffness of the concrete and the FeMnSi-SMA element, respectively; $A_{S M A}$ is the SMA cross-section area, and $L$ is the reference length. During activation, the values of $A_{S M A}, k_{C}$, and $L$ can be considered constant. $E_{S M A}(\kappa)$, however, introduced in the present study as axial modulus, is a variable that depends on the path of the thermo-mechanical process. $\kappa$ in $E_{S M A}(\kappa)$ indicates a different state during prestraining and activation. For example, $E_{S M A}\left(\kappa_{0}\right)$ is the $E_{S M A}$ before pre-straining; $E_{S M A}\left(\kappa_{1}\right)$ is the $E_{S M A}$ of the pre-strained specimen; $E_{S M A}\left(50^{\circ} \mathrm{C} \uparrow\right)$ is the $E_{S M A}$ at $50{ }^{\circ} \mathrm{C}$ in the heating process during activation. It is essential to investigate how the $E_{S M A}(\kappa)$ develops to correctly estimate and model the interaction forces between FeMnSi-SMAs and the other materials. Among numerous studies about FeMnSi-SMAs, there is no research dedicated to the study of the $E_{S M A}(\kappa)$, except some preliminary investigations reported by the present authors in a recent study [21]. This study aims to more comprehensively investigate the $E_{S M A}(\kappa)$ of the novel FeMnSi-SMA.

\section{Materials and Methods}

The investigated material in this study has the composition of Fe-17Mn-5Si-10Cr-4Ni$1(\mathrm{~V}, \mathrm{C}) \mathrm{wt} \%$. It is a hot rolled sheet material (re-fer, Seewen, Switzerland)) with a final cold rolling treatment to reduce the sheet thickness to $1.5 \mathrm{~mm}$. The specimens consist of FeMnSi-SMA strips, which were laser-cut into a final geometry equal to $250 \mathrm{~mm}$ of length, a width of $15 \mathrm{~mm}$, and a thickness of $1.5 \mathrm{~mm}$. The experiment includes two parts. The axial modulus $E_{S M A}(\kappa)$ was evaluated before and after pre-straining (first part), and during the activation process (second part).

\subsection{Test Procedure for Determining $E_{S M A}\left(\kappa_{0}\right)$ before Pre-Straining and $E_{S M A}\left(\kappa_{1}\right)$ after Pre-Straining}

The axial modulus of the as-received specimen $E_{S M A}\left(\kappa_{0}\right)$ was calculated from the stress-strain curve of the tensile loading experiment. The pre-straining tests consist of loading the specimen to $2 \%$ or $4 \%$ and progressively unloading it with the strain rate of $1 \% / \mathrm{min}$. The explanatory stress versus time curve and strain versus time curve during pre-straining can be seen in Figure 3a,b, respectively. The strain values of $2 \%$ and $4 \%$ were chosen based on previous investigation [22]. The pre-straining experiments were conducted on a $250 \mathrm{kN}$ Zwick machine at room temperature. After the pre-straining test, the specimen was re-loaded to $1 \%$ to determine the axial modulus of the pre-strained specimen $E_{S M A}\left(\kappa_{1}\right)$ (Figure 3). Re-loading and unloading were carried out on a Z020 machine (Zwick, Germany) equipped with a climate-controlled chamber (Figure 4). The FeMnSi-SMA specimen was fixed between two clamps, and a clip-on Mini MFA 2 extensometer equipped with an extension arm was installed on the specimen. The gauge length was $100 \mathrm{~mm}$. Both tests were performed at room temperatures of approximately $23^{\circ} \mathrm{C}$. 
(a)

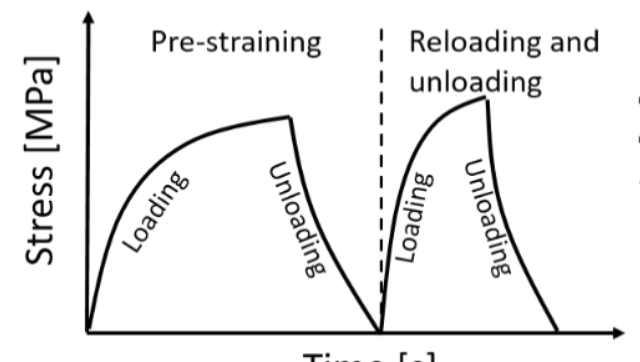

Time $[s]$ (b)

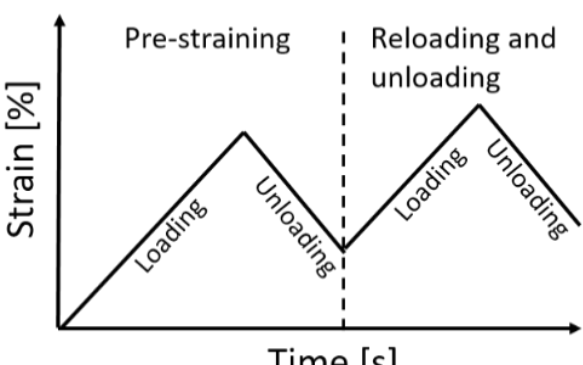

Figure 3. Schematic illustration of the evolution of (a) stress and (b) strain as a function of time during pre-straining and re-loading experiments for determining $E_{S M A}\left(\kappa_{0}\right)$ and $E_{S M A}\left(\kappa_{1}\right)$.

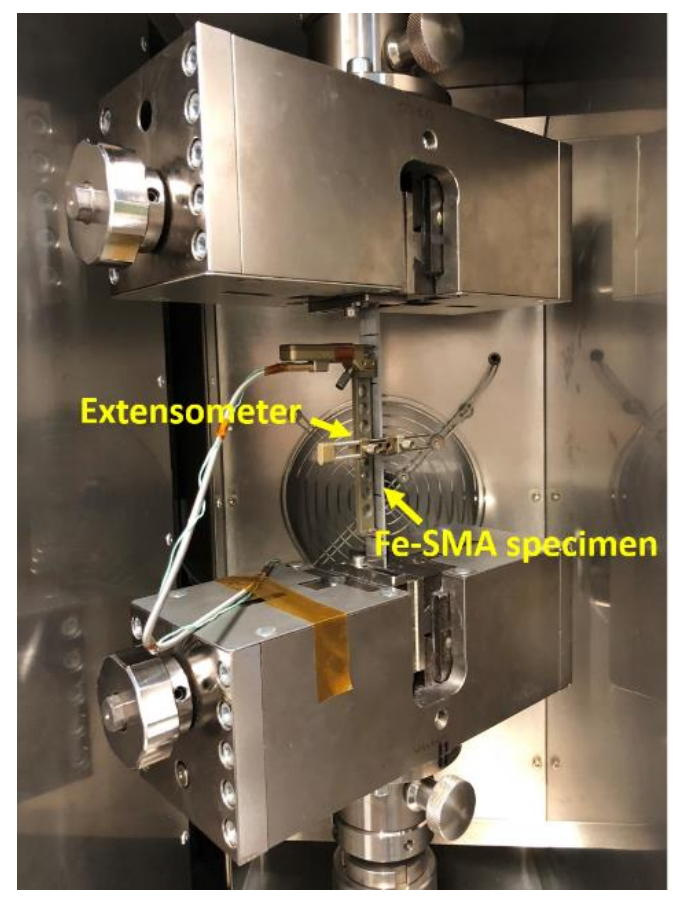

Figure 4. Inner part of the climate chamber on a Z020 Zwick machine: a FeMnSi-SMA specimen was fixed between two clamps, and the clip-on Mini MFA 2 extensometer was installed on the specimen.

\subsection{Test Procedure for the Determination of $E_{S M A}(\kappa)$ during Activation}

$E_{S M A}(\kappa)$ assessment during activation was carried out using the Z020 Zwick machine, equipped with a climate-controlled chamber and the Mini MFA 2 extensometers (Figure 4). All the specimens were previously pre-strained to 2 or $4 \%$. Figure 5 shows an example of a stress-temperature curve during the full activation process. At the beginning of activation (path A), the FeMnSi-SMA specimen was pre-loaded to $50 \mathrm{MPa}$, followed an additional displacement of $10 \mu \mathrm{m}$ to avoid compressive stresses during heating because of the impeded thermal expansion. During the heating process, the axial stress first decreases with the increase of temperature (path B), because the FeMnSi-SMA expands. As the temperature increases, the stress is recovered (path C). This effect is caused by the combined effect of $\varepsilon \rightarrow \gamma$ phase transformation and thermal expansion. The maximum temperature $160{ }^{\circ} \mathrm{C}$ is commonly chosen since at this temperature, significant recovery stress (about $300 \mathrm{MPa}$ ) can be achieved without causing any damage to the concrete [22]. During the cooling process (path D), the axial stress increases with decreasing temperature, which involves thermal contraction of the specimen, phase transformation, and plastic deformation. 


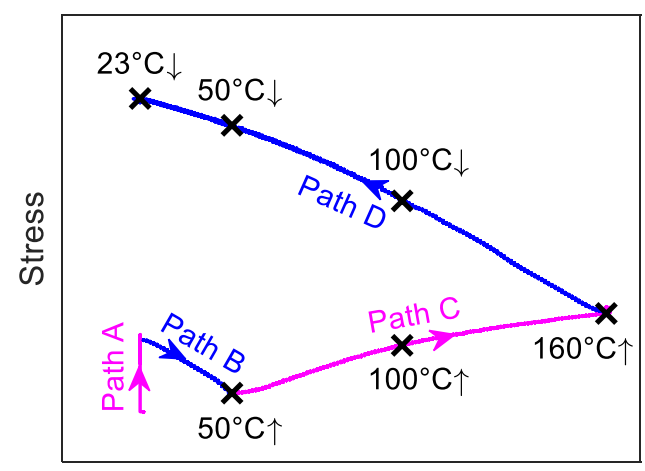

Temperature

Figure 5. Stress versus temperature curve during the activation process. The FeMnSi-SMA is heated up from $23{ }^{\circ} \mathrm{C}$ to $160{ }^{\circ} \mathrm{C}$ and then cooled down to $23^{\circ} \mathrm{C}$. The black cross-marks show the target temperatures of the interrupted thermal-mechanical experiments.

The $E_{S M A}(\kappa)$ during activation was determined by interrupting the activation process and by performing a tensile test at the selected activation step. Figure 6 shows the stress (a), strain (b), and temperature (c) versus time in a thermo-mechanical experiment interrupted at a target temperature, respectively. Under the strain-control conditions, specimens were heated up from $23^{\circ} \mathrm{C}$ to a target temperature at a thermal rate of $2{ }^{\circ} \mathrm{C} / \mathrm{min}$ (Figure 6c). After one hour of waiting at the constant target temperature, specimens were loaded to $1 \%$ strain at a $0.2 \mathrm{~mm} / \mathrm{min}$ rate to determine the $E_{S M A}(\kappa)$. The loading process is marked by "Start" and "End" in Figure 6a,b (red shaded area in Figure 6). Finally, specimens were cooled down and unloaded. Table 1 lists the target temperatures (test temperatures): $50{ }^{\circ} \mathrm{C}$ $\uparrow, 100{ }^{\circ} \mathrm{C} \uparrow$, and $160^{\circ} \mathrm{C} \uparrow$ during heating, and $100^{\circ} \mathrm{C} \downarrow, 50^{\circ} \mathrm{C} \downarrow$ and $23^{\circ} \mathrm{C} \downarrow$ during cooling (' $\uparrow$ ' and ' $\downarrow$ ' indicate that the thermal cycle was interrupted during heating ' $\uparrow$ ' or cooling ' $\downarrow$ '). The target temperatures are also depicted in Figure 5. The selection of $50{ }^{\circ} \mathrm{C} \uparrow$ was because it approximately corresponds to the minimum stress value during the activation process. A temperature between $50{ }^{\circ} \mathrm{C} \uparrow$ and $160{ }^{\circ} \mathrm{C} \uparrow$ was selected, i.e., $100{ }^{\circ} \mathrm{C} \uparrow$. Accordingly, $100{ }^{\circ} \mathrm{C}$ $\downarrow$ and $50^{\circ} \mathrm{C} \downarrow$ were chosen during the cooling process.

Table 1. List of pre-straining and interrupted thermomechanical experiments. The target temperatures of interrupted thermomechanical experiments are $50{ }^{\circ} \mathrm{C} \uparrow, 100{ }^{\circ} \mathrm{C} \uparrow$, and $160{ }^{\circ} \mathrm{C} \uparrow$ during heating, and $100^{\circ} \mathrm{C} \downarrow, 50^{\circ} \mathrm{C} \downarrow$, and $23^{\circ} \mathrm{C} \downarrow$ during cooling (' $\uparrow$ ' and ' $\downarrow$ ' indicate that the thermal cycle was interrupted during heating ' $\uparrow$ ' or cooling ' $\downarrow$ ').

\begin{tabular}{|c|c|c|c|c|}
\hline Process & $\begin{array}{c}\text { Interrupted } \\
\text { Temperature }\left[{ }^{\circ} \mathrm{C}\right]\end{array}$ & Symbol & $\begin{array}{c}\text { Pre-Straining } \\
{[\%]}\end{array}$ & $\begin{array}{c}\text { Experiment } \\
\text { Number }\end{array}$ \\
\hline \multirow{5}{*}{ Heating } & 50 & $50^{\circ} \mathrm{C} \uparrow$ & 2 & 2 \\
\hline & \multirow{2}{*}{100} & \multirow{2}{*}{$100^{\circ} \mathrm{C} \uparrow$} & 2 & 2 \\
\hline & & & 4 & 1 \\
\hline & \multirow{2}{*}{160} & \multirow{2}{*}{$160^{\circ} \mathrm{C} \uparrow$} & 2 & 2 \\
\hline & & & 4 & 1 \\
\hline \multirow{5}{*}{ Cooling } & \multirow{2}{*}{100} & \multirow{2}{*}{$100^{\circ} \mathrm{C} \downarrow$} & 2 & 2 \\
\hline & & & 4 & 1 \\
\hline & \multirow{2}{*}{50} & \multirow{2}{*}{$50^{\circ} \mathrm{C} \downarrow$} & 2 & 2 \\
\hline & & & 4 & 1 \\
\hline & 23 & $23^{\circ} \mathrm{C} \downarrow$ & 2 & 2 \\
\hline
\end{tabular}




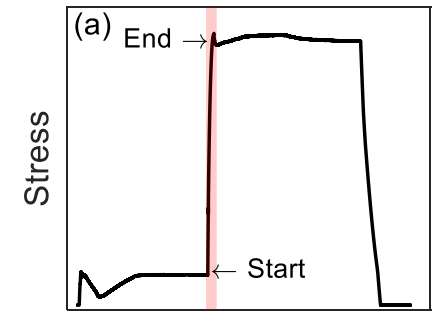

Time

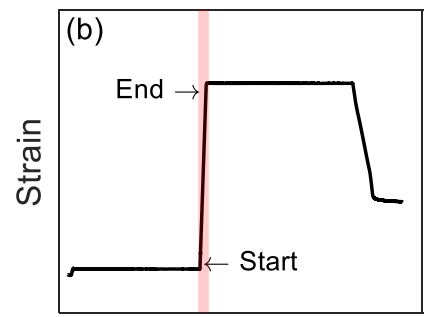

Time

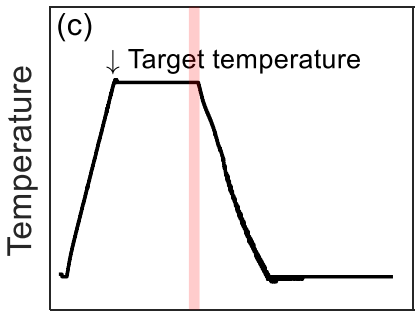

Time

Figure 6. Protocol of the interrupted activation experiment to determine the $E_{S M A}(\kappa)$. (a) Stress, (b) strain, and (c) temperature versus experimental time curves, respectively.

\subsection{Mechanisms Governing the Value of $E_{S M A}(\kappa)$}

During the tensile loading of a normal austenitic stainless steel (without SME), the material will first undergo elastic deformation, which means that the specimen can recover its dimension upon removing the load. In the elastic deformation regime, the external stress leads to the movement of atoms from their equilibrium position but retains their relative positions to each other. Once the stress is removed, all atoms move back to their equilibrium positions. Young's modulus can be derived from the slope of the regression line that fits the experimental data in the elastic loading range of the stress-strain curve. The yield stress represents the upper limit of the elastic regime. It is expected that when the stress reaches this yield stress, plastic deformation involving dislocation movement takes place, and the shape of the specimen cannot be recovered upon removing the load.

For the FeMnSi-SMA, the stress-induced $\varepsilon$-martensite can form with the application of stress at the very beginning of loading [23]. The martensite nucleus can be considered a single stacking fault with a supplementary displacement, which results in a volume dilatation of the FeMnSi-SMA because of martensitic phase transformation [24]. Therefore, besides the movement of atoms from their equilibrium position at the beginning of loading, the supplementary displacement caused by martensite formation will additionally contribute to the measured strain. As a result, at the same stress level, a larger strain is measured for the FeMnSi-SMA compared to a normal austenitic stainless steel. Consequently, a smaller slope of the regression line fitting at the very beginning of the stress-strain curve can be observed, resulting in a smaller modulus value. More $\gamma \rightarrow \varepsilon$ phase transformation can contribute more to the measured strain, and lead to a lower modulus value. As a result, for the FeMnSi-SMA, the measured slope cannot be simply considered as Young's modulus since the $\gamma \rightarrow \varepsilon$ phase transformation is involved. Therefore, axial modulus $E_{S M A}(\kappa)$ is used in this study to characterize the relationship between stress and strain at the early stage of loading instead of Young's modulus.

In general, the $E_{S M A}(\kappa)$ depends on $\gamma \rightarrow \varepsilon$ phase transformation, plastic deformation, initial microstructure (the fraction of austenite and martensite), and temperature. Plastic deformation affects the $E_{S M A}(\kappa)$ by dislocation movement. When the applied stress reaches the yield stress, dislocations start to move, which contributes to the measured strain and affects the $E_{S M A}(\kappa)$. It should be noted that plastic deformation only plays an important role in determining the $E_{S M A}(\kappa)$ when the axial stress gets close to the yield stress of the material at the beginning of loading. For example, for the measurement of $E_{S M A}(\kappa)$ during the cooling process of activation, the axial stress is very high and even reaches the yield stress, and therefore the plastic deformation can already occur at the start of tensile loading (the details can be found in Section 3.2). The temperature and initial microstructure (fraction of austenite and martensite) influence the $E_{S M A}(\kappa)$ mainly by affecting the Young's modulus of the material. In general, the Young's modulus of steel decreases with temperature [25]. On the other hand, the fraction of martensite and austenite phases in the material can affect material's Young's modulus due to the difference of Young's modulus for these two phases. However, such an effect does not play an essential role in determining the axial modulus because of the following reasons and therefore is neglected. Firstly, during pre-straining, only small amount of stress-induced $\varepsilon$-martensite is generated, e.g., about 
$10 \%$ [26]. Furthermore, the difference of Young's modulus is small for austenite and martensite. For example, the Young's modulus of $\gamma$-austenite $E_{A}$ estimated from type 316 austenitic steel is about $207 \mathrm{GPa}$ [27]. The Young's modulus of $\varepsilon$-martensite $E_{M}$ estimated from a type $10 \% \mathrm{Cr}$ martensite steel is about $214 \mathrm{GPa}$ [28]. Therefore, the effect of different amount of $\varepsilon$-martensite and $\gamma$-austenite on material's modulus can be neglected in this study. In a short summary, the $E_{S M A}(\kappa)$ is mainly determined by phase transformation, plastic deformation and temperature.

\section{Results and Discussion}

\subsection{The $E_{S M A}(\kappa)$ before and after Pre-Straining}

Figure 7a shows the stress-strain curve to determine specimen's axial modulus before and after pre-straining. The blue line shows loading to $2 \%$ and unloading to $0 \mathrm{MPa}$ during pre-straining. In the unloading process, the stress-strain curve diverges from a straight line. The diverged strain is the pseudoelasticity $\varepsilon_{p e}$, which is due to back transformation from $\varepsilon$-martensite to $\gamma$-austenite and a reversible motion of Schockley partial dislocations upon unloading [23,29-31]. After pre-straining, the specimen was re-loaded to $1 \%$ and unloaded (black line) to evaluate $E_{S M A}\left(\kappa_{1}\right)$.
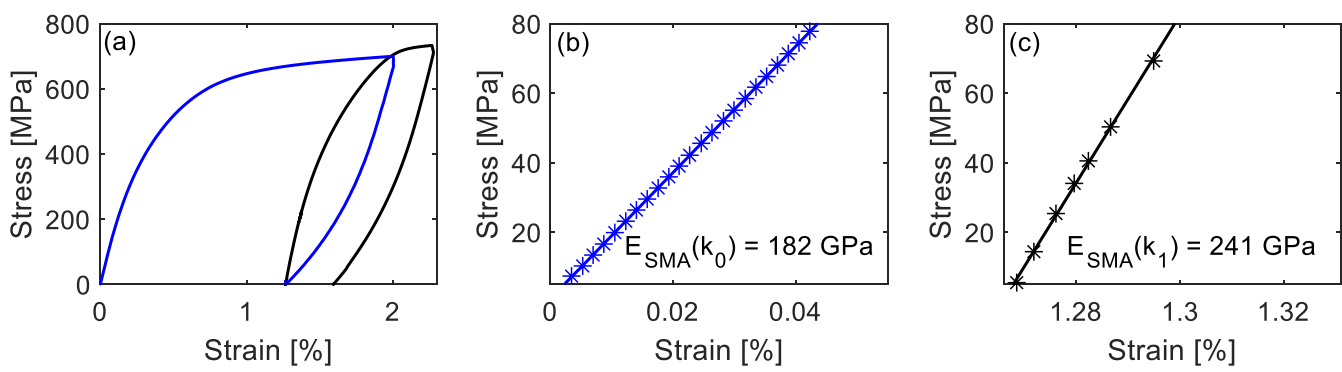

Figure 7. (a) Stress as a function of strain during pre-straining (blue) and re-loading (black); (b) the linear fitting (regression line) in 5-80 MPa of pre-straining; (c) the linear fitting (regression line) in 5-80 MPa of re-loading.

The axial modulus is determined by calculating the slope of linear regression, which most closely fits the initial data of the stress-strain experimental curve. For the sake of consistency, a stress range between 5 and $80 \mathrm{MPa}$ is chosen for all the axial modulus evaluations in this study. The blue line and stars in Figure $7 \mathrm{~b}$ show data points in the 5-80 MPa stress range during pre-straining (blue line in Figure 7a) and the regression line, respectively. The slope of this regression line is the axial modulus of the as-received specimen $E_{S M A}\left(\kappa_{0}\right)$. $E_{S M A}\left(\kappa_{0}\right)$ is determined to be $180 \mathrm{GPa}$ (standard deviation is $6 \mathrm{GPa}$ ) by averaging the values from 19 experiments. The detailed results of these experiments can be found in Table 2. $R^{2}$ shows the goodness-of-fit for the linear regression models and are all higher than 0.999. Similarly, Figure 7c presents data points in the stress range of 5-80 MPa of the re-loading after pre-straining, and the black line is its regression line with slope $E_{S M A}\left(\kappa_{1}\right)$ equal to $241 \mathrm{GPa}$, which is larger than $E_{S M A}\left(\kappa_{0}\right)$.

For the as-received material, during pre-straining, some unstable $\gamma$-austenite transforms into $\varepsilon$-martensite owing to the external stress application. After pre-straining, the amount of unstable $\gamma$-austenite is less in the pre-strained specimen compared to the asreceived one. During re-loading, because of the loss of unstable $\gamma$-austenite, it is expected that less $\gamma \rightarrow \varepsilon$ phase transformation takes place in the pre-strained specimen, resulting in a steeper slope at the beginning of the stress-strain curve, and accordingly, a larger $E_{S M A}\left(\kappa_{1}\right)$ than $E_{S M A}\left(\kappa_{0}\right)$.

On the other hand, it can be seen that the stress during re-loading is higher than that during the initial pre-straining. This is because more $\varepsilon$-martensite was generated after pre-straining, resulting in more significant hardening during the subsequent re-loading. 
Table 2. The detailed $E_{S M A}\left(\kappa_{0}\right)$ values of 19 pre-straining experiments.

\begin{tabular}{cccccccc}
\hline \multicolumn{3}{c}{ Pre-Straining to 2\% } & \multicolumn{3}{c}{ Pre-Straining to 4\% } \\
\hline $\begin{array}{c}E_{S M A}\left(\kappa_{\mathbf{0}}\right) \\
{[\mathrm{GPa}]}\end{array}$ & $\boldsymbol{R}^{\mathbf{2}}$ & $\begin{array}{c}\boldsymbol{E}_{S M A}\left(\kappa_{\mathbf{0}}\right) \\
{[\mathrm{GPa}]}\end{array}$ & $\boldsymbol{R}^{\mathbf{2}}$ & $\begin{array}{c}\boldsymbol{E}_{S M A}\left(\kappa_{\mathbf{0}}\right) \\
{[\mathrm{GPa}]}\end{array}$ & $\boldsymbol{R}^{\mathbf{2}}$ & $\begin{array}{c}\boldsymbol{E}_{S M A}\left(\boldsymbol{\kappa}_{\mathbf{0}}\right) \\
{[\mathrm{GPa}]}\end{array}$ & $\boldsymbol{R}^{\mathbf{2}}$ \\
\hline 175 & 0.9998 & 170 & 0.9999 & 184 & 1.0000 & 173 & 0.9999 \\
174 & 0.9999 & 188 & 1.0000 & 182 & 1.0000 & 183 & 0.9998 \\
182 & 1.0000 & 184 & 0.9999 & 171 & 0.9999 & 188 & 0.9999 \\
189 & 0.9998 & 184 & 1.0000 & 182 & 1.0000 & 185 & 1.0000 \\
178 & 0.9999 & 173 & 1.0000 & & & 178 & 1.0000 \\
\hline
\end{tabular}

\subsection{The $E_{S M A}\left(50^{\circ} \mathrm{C} \uparrow\right)$ and $E_{S M A}\left(50{ }^{\circ} \mathrm{C} \downarrow\right)$ in Activation}

Figure 8 shows the results for the determination of $E_{S M A}(\kappa)$ at $50{ }^{\circ} \mathrm{C} \uparrow$. Figure $8 \mathrm{a}-\mathrm{C}$ depict the stress, strain, and temperature versus time during the $E_{S M A}(\kappa)$ evaluation test. The solid line in Figure $8 \mathrm{~d}$ presents the stress-temperature curve, and the dashed line depicts the plausible development of a full activation process. The black star marks the testing point $\left(50{ }^{\circ} \mathrm{C} \uparrow\right)$, at which $E_{S M A}\left(50{ }^{\circ} \mathrm{C} \uparrow\right)$ is evaluated. Figure 8 e demonstrates the stress-strain curve during loading to $1 \%$ strain. The initial axial stress $\sigma_{0}$ at the beginning of loading, pointed by the arrow, is $29 \mathrm{MPa}$ (also corresponds to the black star in Figure $8 \mathrm{~d}$ ). The $E_{S M A}\left(50^{\circ} \mathrm{C} \uparrow\right)$ is determined by fitting a regression line in the stress ranging from $\sigma_{0}+$ $5 \mathrm{MPa}$ to $\sigma_{0}+80 \mathrm{MPa}$ (the same stress range was used in Section 3.1, which corresponds to a stress range of 34 to $109 \mathrm{MPa}$. Figure $8 \mathrm{f}$ shows the data points used for the fitting of the regression line. The calculated $E_{S M A}\left(50{ }^{\circ} \mathrm{C} \uparrow\right)$ is $239 \mathrm{GPa}$.
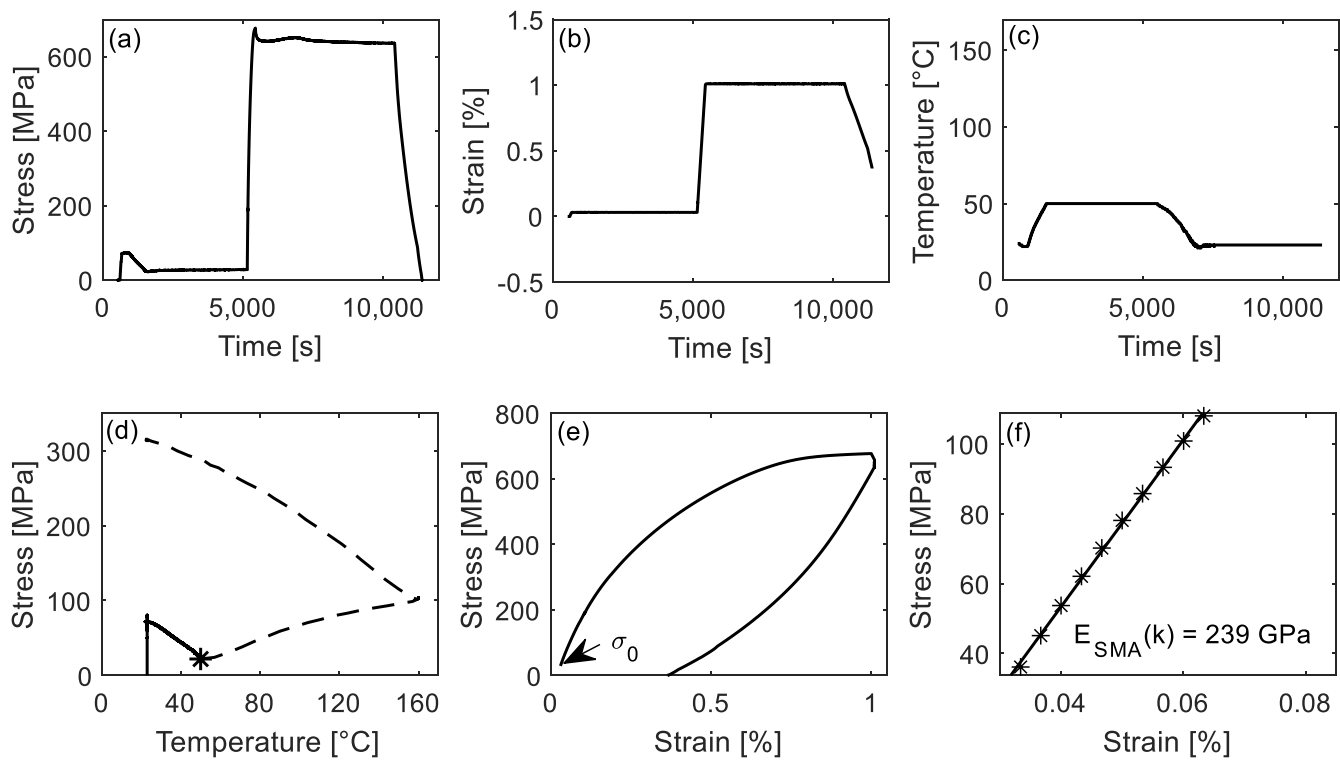

Figure 8. (a-c) Stress, strain and temperature versus time curves of the interrupted experiments to determine $E_{S M A}\left(50{ }^{\circ} \mathrm{C} \uparrow\right)$. (d) Stress as a function of temperature during activation. The black star $\left(50{ }^{\circ} \mathrm{C} \uparrow\right.$ ) marks the point, at which $E_{S M A}$ was evaluated. (e) Stress-strain curve during loading to $1 \%$ strain and unloading. (f) The linear fitting (regression line) in the stress range from $\sigma_{0}+5$ to $\sigma_{0}+$ $80 \mathrm{MPa}$.

Similarly, the assessment of the $E_{S M A}\left(50^{\circ} \mathrm{C} \downarrow\right)$ can be seen in Figure $9 \mathrm{a}-\mathrm{f}$. The $\sigma_{0}$ at $50{ }^{\circ} \mathrm{C} \downarrow$ is $281 \mathrm{MPa}$, and therefore the stress range for the regression is $286-361 \mathrm{MPa}$. The resulting $E_{S M A}\left(50^{\circ} \mathrm{C} \downarrow\right)$ is $145 \mathrm{GPa}$. 

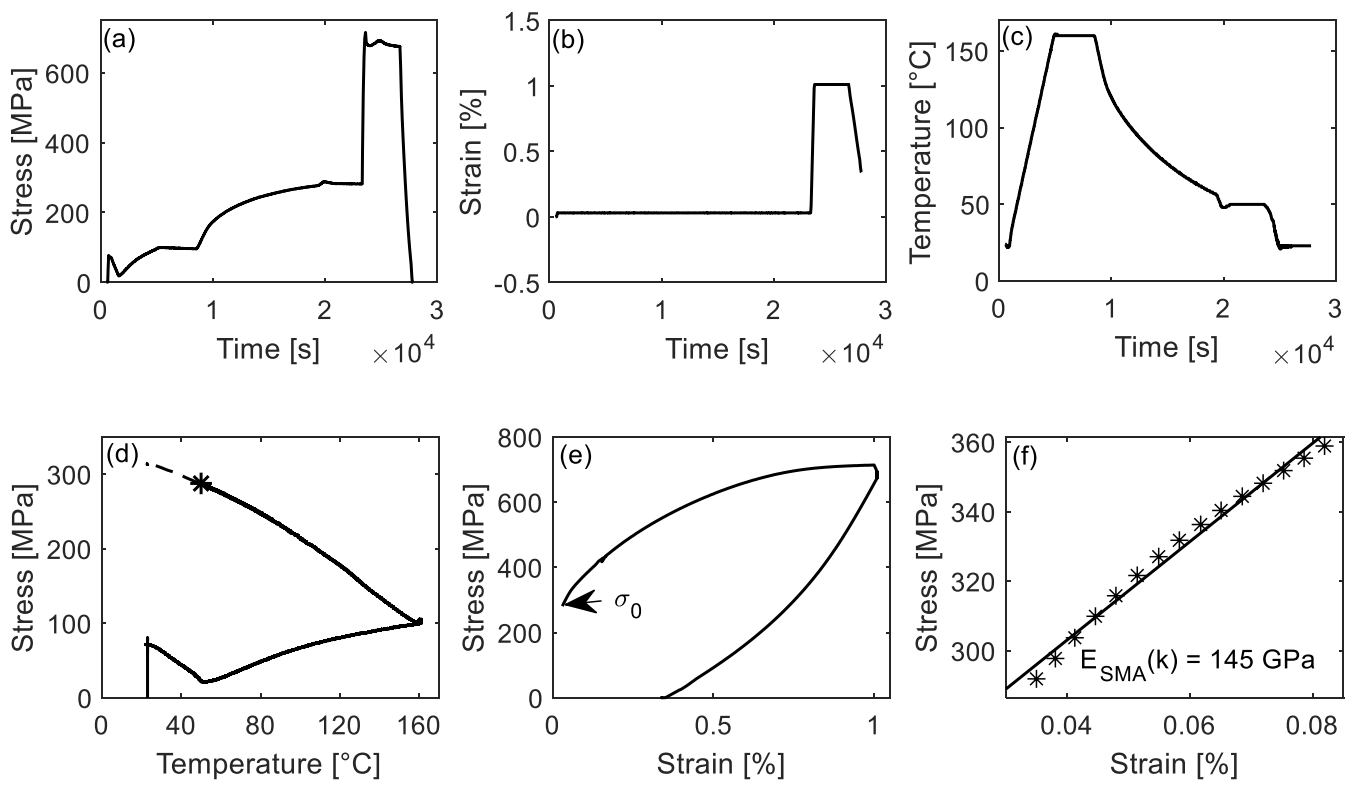

Figure 9. (a-c) Stress, strain, and temperature versus time curves of the interrupted experiments to determine $E_{S M A}\left(50^{\circ} \mathrm{C} \downarrow\right)$. (d) Stress as a function of temperature during activation. The black star $\left(50{ }^{\circ} \mathrm{C} \downarrow\right)$ marks the point, at which $E_{S M A}$ was evaluated. (e) Stress-strain curve during loading to $1 \%$ strain and unloading. (f) The linear fitting (regression line) in the stress range from $\sigma_{0}+5$ to $\sigma_{0}+$ $80 \mathrm{MPa}$.

During the activation process from $50{ }^{\circ} \mathrm{C} \uparrow$ to $50{ }^{\circ} \mathrm{C} \downarrow$, the thermal expansion and contraction effect of the FeMnSi-SMA on the axial stress can be canceled out due to the same temperature value. Since the results show a larger $\sigma_{0}$ at $50{ }^{\circ} \mathrm{C} \downarrow$ than that for $50{ }^{\circ} \mathrm{C}$ $\uparrow$, it is expected that the $\varepsilon \rightarrow \gamma$ phase transformation is dominant during activation and there is more austenite in the specimen at $50{ }^{\circ} \mathrm{C} \downarrow$ than that for $50{ }^{\circ} \mathrm{C} \uparrow$. Consequently, the $\gamma \rightarrow \varepsilon$ phase transformation is more likely to happen at $50^{\circ} \mathrm{C} \downarrow$ and a lower $E_{S M A}(\kappa)$ is observed as mentioned in Section 3.1. In addition, the higher $\sigma_{0}$ at $50{ }^{\circ} \mathrm{C} \downarrow$ can enhance the martensitic phase transformation during loading to $1 \%$ and further lower $E_{S M A}(\kappa)$. On the other hand and at $50{ }^{\circ} \mathrm{C} \downarrow$, the stress range chosen for fitting the regression line is $286-361 \mathrm{MPa}$. The yield stress of the original specimen is $224 \mathrm{MPa}$. This means the regression line is fitted in the stress range of plastic deformation. The measured strain at this stage may involve phase transformation and dislocation movement, which further contributes to the measured strain and leads to a lower slope.

\subsection{The $E_{S M A}(\kappa)$ during the Activation}

Figure 10 summarizes the results of $E_{S M A}(\kappa)$ during activation. Figure 10a shows the points marked by numbers $1-6$, at which the activation process was interrupted, and $E_{S M A}$ was evaluated. Figure $10 \mathrm{~b}$ depicts the corresponding $E_{S M A}(\kappa)$. The black squares and triangles represent the $E_{S M A}(\kappa)$ with $2 \%$ pre-straining during the heating and cooling process, respectively. It can be seen that the $E_{S M A}(\kappa)$ decreases during the heating process and keeps decreasing within the cooling process until the thermal cycle is complete $\left(23^{\circ} \mathrm{C} \downarrow\right)$. The $E_{S M A}\left(\kappa_{0}\right)$ and $E_{S M A}\left(\kappa_{1}\right)$ are also depicted for comparison. As discussed above, $E_{S M A}\left(\kappa_{1}\right)$ is larger than $E_{S M A}\left(\kappa_{0}\right)$. All the experimental values of $E_{S M A}(\kappa)$ together with $\sigma_{0}$ and $R^{2}$ can be found in Table 3. 

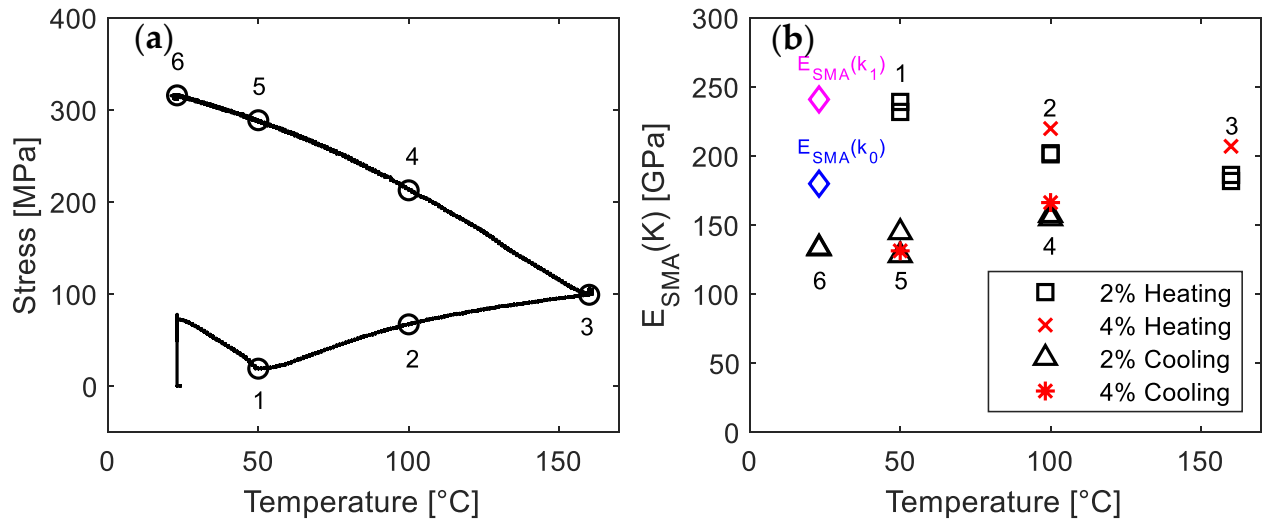

Figure 10. Evolution of $E_{S M A}(\kappa)$ in activation. (a) Number 1-6 show the interrupted temperatures during activation. (b) The corresponding $E_{S M A}(\kappa)$.

Table 3. The values of $\sigma_{0}, E_{S M A}(\kappa)$, and $R^{2}$ at all experimental temperatures in activation.

\begin{tabular}{|c|c|c|c|c|}
\hline $\begin{array}{c}\text { Pre-Straining } \\
{[\%]}\end{array}$ & $\begin{array}{c}\text { Temperature } \\
{\left[{ }^{\circ} \mathrm{C}\right]}\end{array}$ & $\begin{array}{c}\sigma_{0} \\
{[\mathrm{MPa}]}\end{array}$ & $E_{S M A^{\mathrm{K}}}[\mathrm{GPa}]$ & $R^{2}$ \\
\hline 2 & \multirow{3}{*}{$50^{\circ} \mathrm{C} \uparrow$} & 29 & 239 & 0.999 \\
\hline 2 & & 24 & 232 & 0.998 \\
\hline 2 & & 68 & 202 & $1.000^{\mathrm{A}}$ \\
\hline 2 & \multirow[t]{2}{*}{$100^{\circ} \mathrm{C} \uparrow$} & 71 & 201 & 0.999 \\
\hline 4 & & 75 & 220 & 0.998 \\
\hline 2 & \multirow{3}{*}{$160^{\circ} \mathrm{C} \uparrow$} & 92 & 182 & $1.000 \mathrm{~A}$ \\
\hline 2 & & 93 & 186 & 0.999 \\
\hline 4 & & 100 & 207 & 0.999 \\
\hline 2 & \multirow{3}{*}{$100^{\circ} \mathrm{C} \downarrow$} & 217 & 157 & 0.995 \\
\hline 2 & & 219 & 155 & 0.985 \\
\hline 4 & & 225 & 166 & 0.994 \\
\hline 2 & \multirow{3}{*}{$50^{\circ} \mathrm{C} \downarrow$} & 286 & 128 & 0.962 \\
\hline 2 & & 281 & 145 & 0.997 \\
\hline 4 & & 287 & 131 & 0.958 \\
\hline 2 & \multirow{2}{*}{$23^{\circ} \mathrm{C} \downarrow$} & 312 & 133 & 0.983 \\
\hline 2 & & 311 & 134 & 0.983 \\
\hline
\end{tabular}

A Only two experimental points were used for the calculation of the regression.

Figure 11a comprises the $\Delta \sigma$ vs. $\Delta \varepsilon\left(\Delta \sigma=\sigma-\sigma_{0} ; \Delta \varepsilon=\varepsilon-\varepsilon_{0}\right)$ at the beginning of loading phases to determine the $E_{S M A}(\kappa)$. All the presented specimens were pre-strained to $2 \%$. Since the $\sigma_{0}$ is affected by the temperature path, the values are expressed in terms of increment. Figure $11 \mathrm{~b}$ shows the data points in the stress range of 5-80 MPa. It is shown that the slope of the curves (i.e., $E_{S M A}(\kappa)$ ) is decreasing as the entire activation proceeds. It can also be seen in Figure $11 \mathrm{~b}$ that significant plastic deformation occurs for the states during the cooling of activation process (i.e., $23^{\circ} \mathrm{C} \downarrow, 50^{\circ} \mathrm{C} \downarrow$ and $100{ }^{\circ} \mathrm{C} \downarrow$ ), and hence leads to lower $E_{S M A}(\kappa)$.

During the heating process, both $\sigma_{0}$ and the fraction of austenite keep increasing after the point $50{ }^{\circ} \mathrm{C} \uparrow$. Consequently, the higher $\sigma_{0}$ and larger amount of austenite for the later stage of the heating process can result in a larger extent of the phase transformation during the tensile loading, and hence lead to smaller $E_{S M A}(\kappa)$. On the other hand, during the cooling, the values of $\sigma_{0}$ may reach the yield stress of the material, and therefore plastic deformation can occur at the early stage of the tensile experiment, which is expected to contribute to the reduction of $E_{S M A}(\kappa)$ with decreasing temperature. It should be noted that the Young's modulus increases with decreasing temperature for the normal material without SME. The observed smaller $E_{S M A}(\kappa)$ at lower temperature during the cooling of activation process indicates that the effect of phase transformation and plastic deformation on $E_{S M A}(\kappa)$ is more significant than that of temperature for the presented case. 

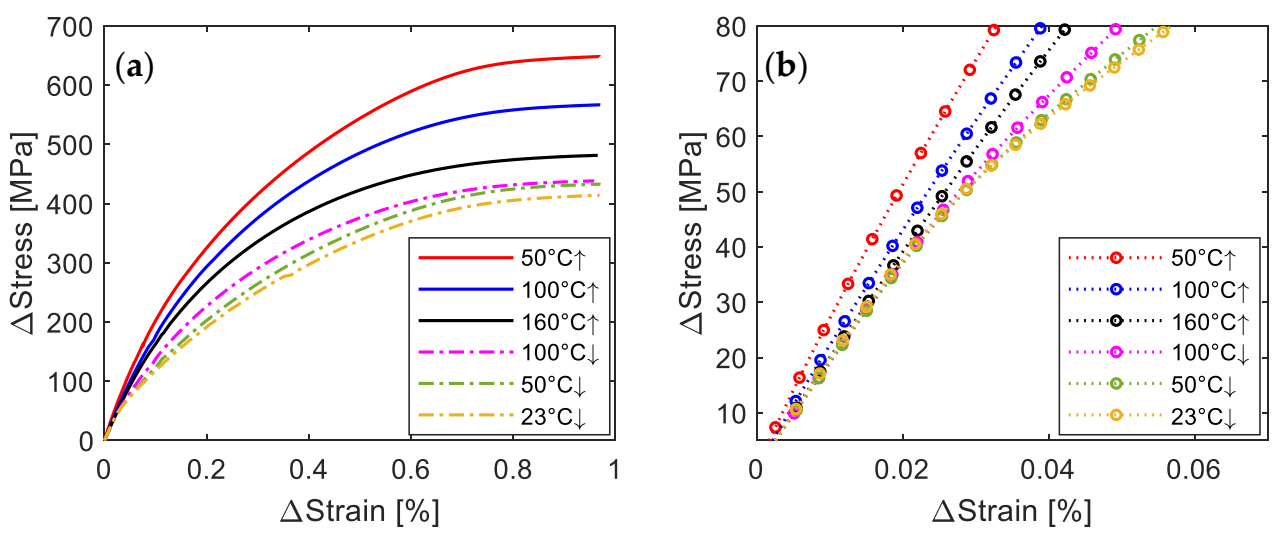

Figure 11. (a) Representative $\Delta$ stress- $\Delta$ strain curves during loading to $1 \%$. The initial $\Delta$ stress $/ \Delta$ strain is set to be zero. (b) The experimental data in the stress range of 5-80 MPa.

The $E_{S M A}(\kappa)$ of the specimens pre-strained to $4 \%$ was indicated by red cross-marks (heating process) and red star-marks (cooling process) in Figure 10b. Similar to the trend observed for the specimens pre-strained to $2 \%$, the $E_{S M A}(\kappa)$ keeps decreasing until the thermal cycle is complete. However, compared to $2 \%$ pre-strained specimens, the values of $E_{S M A}(\kappa)$ for the specimens pre-strained to $4 \%$ are slightly larger at the same heating temperature. For example, Figure $12 \mathrm{a}-\mathrm{c}$ compare the determination of $E_{S M A}(\kappa)$ at $160^{\circ} \mathrm{C}$ $\uparrow$ for the specimens pre-strained to $2 \%$ (black color) and $4 \%$ (red color). It can be seen in Figure $12 \mathrm{~b}$ that the initial axial stresses $\sigma_{0}$ of both specimens are almost equal, but the specimen pre-strained to $4 \%$ shows a higher slope (red line in Figure $12 b, c)$. This is because pre-straining to $4 \%$ can result in a larger extent of phase transformation from unstable austenite to martensite in comparison to $2 \%$ pre-straining, which makes the $\gamma \rightarrow \varepsilon$ phase transformation during the loading to $1 \%$ at the $E_{S M A}$ testing point more difficult and results in a higher $E_{S M A}(\kappa)$.
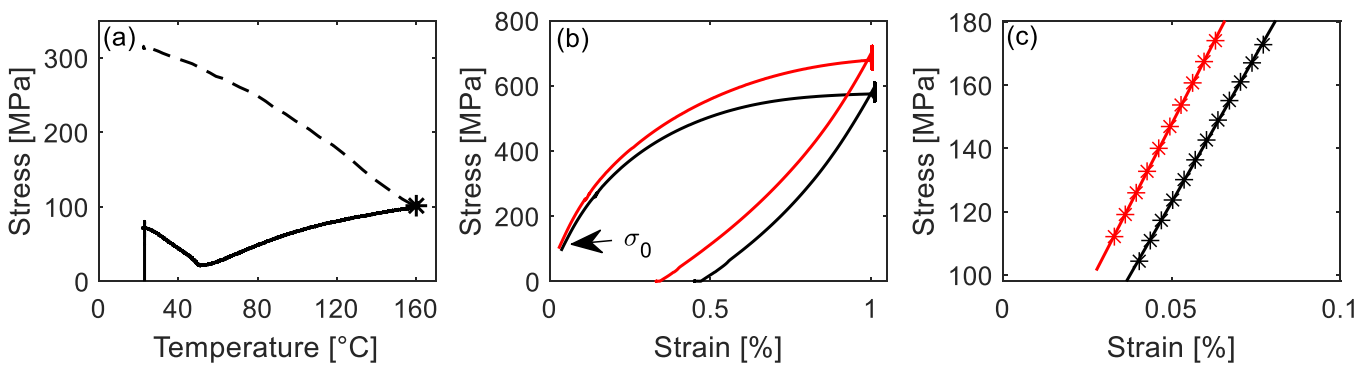

Figure 12. (a) Stress vs. temperature up to the target temperature (The dashed line shows the expected path for full activation). The black star $\left(50^{\circ} \mathrm{C} \uparrow\right)$ marks the point, at which $E_{S M A}$ was evaluated. (b) Stress-strain curve to determine the $E_{S M A}(\kappa)$. (c) The linear fitting (regression line) in the stress range from $\sigma_{0}+5$ to $\sigma_{0}+80 \mathrm{MPa}$. Red and black lines in $(\mathbf{b}, \mathbf{c})$ represent the specimen pre-strained to $4 \%$ and $2 \%$, respectively.

\section{Conclusions and Outlook}

In this study, the axial modulus $E_{S M A}(\kappa)$ of FeMnSi-SMAs has been investigated during and after pre-straining as well as in the course of the activation processes. The experimental observations can be summarized as follows:

- The $E_{S M A}(\kappa)$ is mainly determined by phase transformation, plastic deformation and temperature.

- The axial modulus during the re-loading after pre-straining is larger than that during the pre-straining. This is because the amount of unstable $\gamma$-austenite is less in the pre-strained specimen compared to the as-received alloy, resulting in less $\gamma \rightarrow \varepsilon$ phase 
transformation in the pre-strained specimen at the beginning of the stress-strain curve, and accordingly, a larger $E_{S M A}\left(\kappa_{1}\right)$ than $E_{S M A}\left(\kappa_{0}\right)$.

- The evolution of $E_{S M A}(\kappa)$ during the activation process of the specimens initially pre-strained to $2 \%$ and $4 \%$ keeps decreasing as the activation process proceeds until the thermal cycle is done. At the later stage of the activation process and during the tensile loading for $E_{S M A}(\kappa)$ evaluation, more $\gamma \rightarrow \varepsilon$ phase transformation and plastic deformation can occur, and therefore lead to a smaller $E_{S M A}(\kappa)$.

- The values of $E_{S M A}(\kappa)$ for the specimens initially pre-strained to $4 \%$ are slightly larger than those for the specimens initially pre-strained to $2 \%$ at the same heating temperature. This is because pre-straining to $4 \%$ can result in a larger extent of $\gamma \rightarrow \varepsilon$ phase transformation (and plastic deformation) in comparison to $2 \%$ pre-straining, and therefore lead to less $\gamma \rightarrow \varepsilon$ phase transformation during the tensile loading at the $E_{S M A}$ testing point, i.e., a higher $E_{S M A}(\kappa)$.

- Microstructure investigation (e.g., electron backscattered diffraction and X-ray diffraction) is recommended in future work to characterize the phase transformation during the pre-straining and activation process.

Author Contributions: Conceptualization, Y.Y., M.B. and M.S.; methodology, Y.Y., M.B. and M.S.; software, Y.Y., M.B. and M.S.; validation, Y.Y., M.B. and M.S.; formal analysis, Y.Y., M.B. and M.S.; investigation, Y.Y., M.B. and M.S.; resources, Y.Y., M.B. and M.S.; data curation, Y.Y., M.B. and M.S.; writing—original draft preparation, Y.Y.; writing—review and editing, Y.Y., M.B. and M.S.; visualization, Y.Y., M.B. and M.S.; supervision, M.B. and M.S.; project administration, M.S.; funding acquisition, Y.Y. and M.S. All authors have read and agreed to the published version of the manuscript.

Funding: Financial support from China Scholarship Council (File No. 201808080209) and Engineering Sciences department at EMPA in Switzerland is gratefully acknowledged.

Institutional Review Board Statement: Not applicable.

Informed Consent Statement: Not applicable.

Data Availability Statement: All raw/processed data necessary for reproducing results in this study can be accessed on reasonable request.

Acknowledgments: The authors are grateful to company re-fer AG (Switzerland) for providing the investigated FeMnSi-SMA.

Conflicts of Interest: The authors declare no conflict of interest.

\section{References}

1. Stoeckel, D. Shape memory actuators for automotive applications. Mater. Des. 1990, 11, 302-307. [CrossRef]

2. Sawaguchi, T.; Sahu, P.; Kikuchi, T.; Ogawa, K.; Kajiwara, S.; Kushibe, A.; Higashino, M.; Ogawa, T. Vibration mitigation by the reversible fcc/hcp martensitic transformation during cyclic tension-compression loading of an Fe-Mn-Si-based shape memory alloy. Scr. Mater. 2006, 54, 1885-1890. [CrossRef]

3. Kim, B.; Lee, M.G.; Lee, Y.P.; Kim, Y.; Lee, G. An earthworm-like micro robot using shape memory alloy actuator. Sens. Actuators A Phys. 2006, 125, 429-437. [CrossRef]

4. Hartl, D.J.; Lagoudas, D.C. Aerospace applications of shape memory alloys. Proc. Inst. Mech. Eng. Part G J. Aerosp. Eng. 2007, 221, 535-552. [CrossRef]

5. Schranz, B.; Michels, J.; Czaderski, C.; Motavalli, M.; Vogel, T.; Shahverdi, M. Strengthening and prestressing of bridge decks with ribbed iron-based shape memory alloy bars. Eng. Struct. 2021, 241, 112467. [CrossRef]

6. Yang, Y.; Arabi-Hashemi, A.; Leinenbach, C.; Shahverdi, M. Influence of thermal treatment conditions on recovery stress formation in an FeMnSi-SMA. Mater. Sci. Eng. A 2021, 802, 140694. [CrossRef]

7. Yang, Y.; Arabi-Hashemi, A.; Leinenbach, C.; Shahverdi, M. Improvement of FeMnSi Based Shape Memory Alloys Yield Stress by Heat Treatment. In Proceedings of the 5th SMAR Conference, Potsdam, Germany, 27-29 August 2019.

8. Arabi-Hashemi, A.; Polatidis, E.; Smid, M.; Panzner, T.; Leinenbach, C. Grain orientation dependence of the forward and reverse fcc $\leftrightarrow$ hcp transformation in FeMnSi-based shape memory alloys studied by in situ neutron diffraction. Mater. Sci. Eng. A 2020, 782, 139261. [CrossRef]

9. Arabi-Hashemi, A.; Lee, W.; Leinenbach, C. Recovery stress formation in FeMnSi based shape memory alloys: Impact of precipitates, texture and grain size. Mater. Des. 2018, 139, 258-268. [CrossRef] 
10. Kajiwara, S. Characteristic features of shape memory effect and related transformation behavior in Fe-based alloys. Mater. Sci. Eng. A 1999, 273, 67-88. [CrossRef]

11. Cladera, A.; Weber, B.; Leinenbach, C.; Czaderski, C.; Shahverdi, M.; Motavalli, M. Iron-based shape memory alloys for civil engineering structures: An overview. Constr. Build. Mater. 2014, 63, 281-293. [CrossRef]

12. Czaderski, C.; Shahverdi, M.; Ghafoori, E.; Motavalli, M.; Leinenbach, C.; Arabi-Hashemi, A.; Michels, J.; Scherer, J. The development of memory steel at Empa. In Proceedings of the 5th International Conference on Smart Monitoring, Assessment and Rehabilitation of Civil Structures (SMAR), Potsdam, Germany, 27-29 August 2019.

13. Re-fer Strengthening Solutions. Available online: www.re-fer.eu (accessed on 18 April 2020).

14. Schranz, B.; Czaderski, C.; Vogel, T.; Shahverdi, M. Bond investigations of prestressed, near-surface-mounted, ribbed memorysteel bars with full bond length. Mater. Des. 2020, 196, 109145. [CrossRef]

15. Abouali, S.; Shahverdi, M.; Ghassemieh, M.; Motavalli, M. Nonlinear simulation of reinforced concrete beams retrofitted by near-surface mounted iron-based shape memory alloys. Eng. Struct. 2019, 187, 133-148. [CrossRef]

16. Dolatabadi, N.; Shahverdi, M.; Ghassemieh, M.; Motavalli, M. RC Structures Strengthened by an Iron-Based Shape Memory Alloy Embedded in a Shotcrete Layer-Nonlinear Finite Element Modeling. Materials 2020, 13, 5504. [CrossRef]

17. Schranz, B.; Czaderski, C.; Vogel, T.; Shahverdi, M. Bond behaviour of ribbed near-surface-mounted iron-based shape memory alloy bars with short bond lengths. Mater. Des. 2020, 191, 108647. [CrossRef]

18. Michels, J.; Shahverdi, M.; Czaderski, C. Flexural strengthening of structural concrete with iron-based shape memory alloy strips. Struct. Concr. 2018, 19, 876-891. [CrossRef]

19. Shahverdi, M.; Czaderski, C.; Motavalli, M. Iron-based shape memory alloys for prestressed near-surface mounted strengthening of reinforced concrete beams. Constr. Build. Mater. 2016, 112, 28-38. [CrossRef]

20. Lee, W.; Weber, B.; Leinenbach, C. Recovery stress formation in a restrained Fe-Mn-Si-based shape memory alloy used for prestressing or mechanical joining. Constr. Build. Mater. 2015, 95, 600-610. [CrossRef]

21. Yang, Y.; Breveglieri, M.; Shahverdi, M. Axial stiffness of an Fe-SMA during the activation process. In Proceedings of the SMAR 2019-Fifth Conference on Smart Monitoring, Assessment and Rehabilitation of Civil Structures, Potsdam, Germany, 27-29 August 2019; pp. 1-8.

22. Shahverdi, M.; Michels, J.; Czaderski, C.; Motavalli, M. Iron-based shape memory alloy strips for strengthening RC members: Material behavior and characterization. Constr. Build. Mater. 2018, 173, 586-599. [CrossRef]

23. Leinenbach, C.; Arabi-Hashemi, A.; Lee, W.; Lis, A.; Sadegh-Ahmadi, M.; Van Petegem, S.; Panzner, T.; Van Swygenhoven, H. Characterization of the deformation and phase transformation behavior of VC-free and VC-containing FeMnSi-based shape memory alloys by in situ neutron diffraction. Mater. Sci. Eng. A 2017, 703, 314-323. [CrossRef]

24. Brooks, J.; Loretto, M.; Smallman, R. Direct observations of martensite nuclei in stainless steel. Acta Metall. 1979, $27,1839-1847$. [CrossRef]

25. Gardner, L.; Insausti, A.; Ng, K.; Ashraf, M. Elevated temperature material properties of stainless steel alloys. J. Constr. Steel Res. 2010, 66, 634-647. [CrossRef]

26. Leinenbach, C.; Lee, W.; Lis, A.; Arabi-Hashemi, A.; Cayron, C.; Weber, B. Creep and stress relaxation of a FeMnSi-based shape memory alloy at low temperatures. Mater. Sci. Eng. A 2016, 677, 106-115. [CrossRef]

27. Ledbetter, H. Dynamic vs. static Young's moduli: A case study. Mater. Sci. Eng. A 1993, 165, L9-L10. [CrossRef]

28. Zhang, Q.; Zhang, J.; Zhao, P.; Huang, Y.; Yu, Z.; Fang, X. Low-cycle fatigue behaviors of a new type of $10 \%$ Cr martensitic steel and welded joint with Ni-based weld metal. Int. J. Fatigue 2016, 88, 78-87. [CrossRef]

29. Li, X.; Holdsworth, S.R.; Mazza, E.; Hosseini, E. Comparison of primary creep regeneration and anelastic recovery behaviour of $316 \mathrm{H}$ austenitic and $10 \% \mathrm{Cr}$ martensitic steels. Mech. Mater. 2020, 148, 103474. [CrossRef]

30. Li, X.; Holdsworth, S.; Kalácska, S.; Balogh, L.; Park, J.-S.; Dasilva, Y.A.R.; Maeder, X.; Cocks, A.; Mazza, E.; Hosseini, E. In-situ and ex-situ microstructure studies and dislocation-based modelling for primary creep regeneration response of $316 \mathrm{H}$ stainless steel. Acta Mater. 2021, 216, 117130. [CrossRef]

31. Li, X.; Holdsworth, S.R.; Kalácska, S.; Balogh, L.; Park, J.-S.; Sologubenko, A.; Maeder, X.; Kabra, S.; Mazza, E.; Hosseini, E. Primary creep regeneration in 10\% Cr martensitic steel: In-situ and ex-situ microstructure studies. Mater. Des. 2021, $199,109405$. [CrossRef] 